\title{
Correction: A Mobile App (FallSA) to Identify Fall Risk Among Malaysian Community-Dwelling Older Persons: Development and Validation Study
}

Devinder Kaur Ajit Singh ${ }^{1 *}$, PhD; Jing Wen Goh ${ }^{1 *}$, BSc; Muhammad Iqbal Shaharudin ${ }^{1,2 *}$, MSc; Suzana Shahar ${ }^{1 *}$, $\mathrm{PhD}$

${ }^{1}$ Center for Healthy Ageing and Wellness, Faculty of Health Sciences, Universiti Kebangsaan Malaysia, Kuala Lumpur, Malaysia

${ }^{2}$ Faculty of Health Sciences, Cawangan Pulau Pinang, Kampus Bertam, Universiti Teknologi Majlis Amanah Rakyat, Penang, Malaysia

*all authors contributed equally

\section{Corresponding Author:}

Devinder Kaur Ajit Singh, PhD

Center for Healthy Ageing and Wellness

Faculty of Health Sciences

Universiti Kebangsaan Malaysia

Jalan Raja Muda Abdul Aziz

Kuala Lumpur, 50300

Malaysia

Phone: 60392897000

Email: devinder@ukm.edu.my

\section{Related Article:}

Correction of: https://mhealth.jmir.org/2021/10/e23663

(JMIR Mhealth Uhealth 2021;9(10):e34368) doi: 10.2196/34368

In "A Mobile App (FallSA) to Identify Fall Risk Among Malaysian Community-Dwelling Older Persons: Development and Validation Study" (JMIR Mhealth Uhealth 2021;9(10):e23663), the authors noted one error.

In the originally published manuscript, the name of author Devinder Kaur Ajit Singh was formatted incorrectly as the given name "Devinder" and surname "Kaur Ajit Singh." This has now been corrected to the given names "Devinder Kaur Ajit" and surname "Singh." The citation information for this author has also been corrected from "Kaur Ajit Singh D" to "Singh DKA."

The correction will appear in the online version of the paper on the JMIR Publications website on October 28, 2021, together with the publication of this correction notice. Because this was made after submission to PubMed, PubMed Central, and other full-text repositories, the corrected article has also been resubmitted to those repositories.

This is a non-peer-reviewed article. Submitted 19.10.21; accepted 20.10.21; published 28.10.21.

Please cite as:

Singh DKA, Goh JW, Shaharudin MI, Shahar S

Correction: A Mobile App (FallSA) to Identify Fall Risk Among Malaysian Community-Dwelling Older Persons: Development and Validation Study

JMIR Mhealth Uhealth 2021;9(10):e34368

URL: https://mhealth.jmir.org/2021/10/e34368

doi: $10.2196 / 34368$

PMID:

CDevinder Kaur Ajit Singh, Jing Wen Goh, Muhammad Iqbal Shaharudin, Suzana Shahar. Originally published in JMIR mHealth and uHealth (https://mhealth.jmir.org), 28.10.2021. This is an open-access article distributed under the terms of the Creative Commons Attribution License (https://creativecommons.org/licenses/by/4.0/), which permits unrestricted use, distribution, and reproduction in any medium, provided the original work, first published in JMIR mHealth and uHealth, is properly cited. The 
complete bibliographic information, a link to the original publication on https://mhealth.jmir.org/, as well as this copyright and license information must be included. 